\title{
TRANSIÇÃO EM INFRAESTRUTURAS URBANAS \\ DE CONTROLE PLUVIAL: UMA ESTRATÉGIA \\ PAISAGÍSTICA DE ADAPTAÇÃO \\ ÀS MUDANÇAS CLIMÁTICAS
}

\author{
TRANSITION IN URBAN STORMWATER MANAGEMENT INFRASTRUCTURES: \\ A LANDSCAPE ESTRATEGY FOR CLIMAGE CHANGING
}

\author{
Newton Celio Becker Moura* \\ Paulo Renato Mesquita Pellegrino** \\ José Rodolfo Scarati Martins***
}

\section{RESUMO}

Projeções em modelos climáticos globais quanto às emissões de gases de efeito estufa apontam um aumento na intensidade e frequência dos eventos extremos de chuva, que, associado ao crescimento urbano e à expansão das superfícies impermeáveis, deverá gerar impactos sem precedentes sobre a infraestrutura de drenagem. Diante desse cenário, as cidades têm a oportunidade de realizar uma transição infraestrutural ao adotar técnicas de Melhores Práticas de Manejo (MPM) das águas de chuva como solução mais sustentável, resiliente e integrada à paisagem urbana. Este estudo apresenta uma comparação qualiquantitativa entre reservatórios de detenção e MPM dos escoamentos como estratégias de controle pluvial. Considerando uma microbacia urbana na Região Metropolitana de São Paulo (RMSP), onde foram instalados dois reservatórios com volume de detenção total de $19.200 \mathrm{~m}^{3}$, distribuíram-se elementos de biorretenção e passeios porosos nas vias públicas localizadas na área de contribuição da bacia. O volume de retenção das técnicas propostas como tratamento dos espaços abertos públicos corresponde a $42 \%$ da capacidade de detenção dos reservatórios. Confirma-se, então, a viabilidade das MPM como alternativas para adaptação das cidades às mudanças climáticas,

* Arquiteto pela Universidade Federal do Ceará (UFC). Doutorando na Faculdade de Arquitetura e Urbanismo da Universidade de São Paulo (FAUUSP). Avenida Humberto Monte, s.n., Campus do Pici, Edifício da Coordenadoria de Projetos e Obras, 60455-760, Fortaleza, CE, Brasil. newtonbecker@usp.br

** Arquiteto pela Pontifícia Universidade Católica de Campinas (PUC-Campinas). Mestre, doutor e pós-doutor pela Faculdade de Arquitetura e Urbanismo da Universidade de São Paulo (FAUUSP). Departamento de Projeto da FAUUSP. Rua do Lago, 876, Cidade Universitária, Butantã, 05508900, caixa-postal 51623, São Paulo, SP, Brasil.

prmpelle@usp.br

*** Engenheiro pela Escola Politécnica da Universidade de São Paulo (Poli/USP). Mestre e doutor em Engenharia Civil. Departamento de Engenharia Hidráulica e Ambiental da Poli/USP. Avenida Professor Almeida Prado, s.n., Edifício da Engenharia Civil, 05508-900, São Paulo, SP, Brasil. scarati@usp.br 
desde que levadas em conta as especificidades ambientais e paisagísticas locais no desenho desses elementos como forma de garantir a sua eficiência.

Palavras-chave: Mudanças climáticas. Drenagem urbana. Melhores Práticas de Manejo. São Paulo.

\section{ABSTRACT}

Global climate models regarding the predicted scenarios of Greenhouse Gases (GHG) emissions, forecast a general increase in intensity and frequency of extreme rainfalls. Advanced studies in regional and local scales attest this intensification with greater spatial and temporal precision. The increase in rainfall associated with urban sprawl and more impervious surfaces, will lead to unprecedented impacts on drainage infrastructures. Facing the need of adaption to this future scenario, cities have the opportunity to perform an infrastructural transition when adopting stormwater Best Management Practices (BMPs) as a sustainable, resilient and landscape friendly solution. This paper presents a qualitative and quantitative comparison between BMPs techniques and usual detention reservoirs as flow control strategies. Regarding a case study urban watershed in Greater São Paulo, where two reservoirs with total volume of $19.200 \mathrm{~m}^{3}$ were built, porous sidewalks and bioretention elements have been located in the contribution area within this basin. The retention volume of these proposed techniques considering their average porosity corresponds to $42 \%$ of the reservoirs capacity. It is then confirmed stormwater BMPs viability and suitability as alternatives to adapting cities to climate change, but their efficiency relies on a design that takes into account the specific local environment and landscape.

Keywords: Climate change. Urban drainage. Best Management Practices. São Paulo.

\section{INTRODUÇÃO}

Existe, atualmente, uma urgência global em desenvolver novas linguagens e novas ferramentas de engenharia e construção para que possamos viver sem exaurir a natureza. Essas soluções estão na escala da paisagem e implicam trabalhar em uma escala maior, entender como ela funciona e projetar em harmonia com a estrutura do sistema natural que nos sustenta. (DRAMSTAD; OLSON; FORMAN, 1996). Nesse sentido, devemos aplicar criatividade aos sistemas naturais para que eles possam atender aos desafios da infraestrutura urbana, especialmente aqueles relacionados à drenagem e à qualidade da água. (CORMIER; PELLEGRINO, 2006; NOVOTNY; AHERN; BROWN, 2010).

As mudanças climáticas iminentes, relacionadas às emissões de gases de efeito estufa (GEE), reforçam esse desafio urgente de adaptação das cidades, onde vive a maior parcela da população mundial. Os cenários previstos de impactos ambientais sobre as infraestruturas urbanas, tais como o aumento generalizado na intensidade e frequência de eventos extremos de chuva, exigem tecnologias mais sustentáveis, que possam mitigar o problema e configurar áreas urbanas mais resilientes.

Nesse contexto, considerando a intensificação da demanda e sobrecarga sobre as infraestruturas de drenagem e controle pluvial, as Melhores Práticas de Manejo (MPM) das águas de chuva são analisadas como possibilidades técnicas quando aliadas ao paisagismo. Quando comparadas às soluções convencionais, como reservatórios de detenção, surgem como alternativas aos inconvenientes evidenciados nos chamados piscinões, que, mesmo demonstrando resultados eficazes na redução de enchentes, apresentam problemas na sua manutenção e operacionalização. 


\section{MAIS CHUVAS INTENSAS, MAIS IMPACTOS SOBRE A DRENAGEM URBANA}

As mudanças climáticas deverão alterar a intensidade e a frequência dos eventos extremos de chuva' em todo o planeta. Projeções simuladas por modelos climáticos reforçam um aumento generalizado das precipitações extremas no clima futuro como resultado do aquecimento global atribuído à elevação nas emissões e concentrações dos gases de efeito estufa (GEE). (MAILHOT; DUCHESNE, 2010).

Algumas pesquisas científicas de destaque ${ }^{2}$ têm investigado esse campo temático (tabela 1), sendo referências para projeções em escalas regionais e para estabelecer políticas de mitigação das emissões e de adaptação aos efeitos das mudanças climáticas previstas. (IPCC, 2007). Estudos conduzidos para localidades específicas ${ }^{3}$, por sua vez, já detectaram alterações recentes no padrão de chuvas mais intensas, confirmando que o aumento nas precipitações extremas já é realidade em alguns locais ou regiões.

A maior intensidade e frequência das chuvas terá, certamente, impactos sobre a drenagem urbana. Atualmente, o projeto da infraestrutura de drenagem nas cidades é baseado em análises estatísticas quanto à relação intensidade/duração/frequência de eventos climáticos já ocorridos. O seu dimensionamento é calculado para suportar vazões específicas, considerando o período de retorno de eventos de maior magnitude, como chuvas de cem anos. (DENAULT; MILLAR; LENCE, 2006).

Tradicionalmente, portanto, os parâmetros estatísticos das variáveis hidrológicas para esse dimensionamento são considerados constantes ao longo do tempo, sem grandes flutuações, e são ditos estacionários. Contudo, com a contribuição das mudanças climáticas na alteração dos padrões conhecidos de intensidade e frequência das precipitações, esse modelo estacionário de cálculo torna-se inadequado e, se mantido como método utilizado, aumentará a probabilidade de sobrecarga nos sistemas de drenagem urbana e o risco de enchentes. (MAILHOT; DUCHESNE, 2010; DENAULT, MILLAR; LENCE, 2006; GUO, 2006).

A classificação das precipitações como intensas depende dos padrões das chuvas regionais ou locais. Os estudos revisados neste artigo consideram a relação intensidade/duração/frequência para definir os eventos extremos de chuva. (MAILHOT; DUCHESNE, 2010).

2 As produções científicas elencadas na tabela 1 foram selecionadas pelo número relevante de citações no sistema de pesquisa scopus (Del Genio et al.: 32 citações; Frei et al.: 89 citações; Emori et al.: 50 citações) e por coincidirem como referências entre os artigos desta revisão bibliográfica.

3 Chicago, nos EUA (CHANGNON; WESTCOTT, 2002); Itália (BRUNETTI et al., 2004); Vancouver, no Canadá (DENAULT et al., 2006); Região Sudeste da América do Sul - Brasil, Argentina, Paraguai e Uruguai. (RE et al., 2009). Em todos os estudos, verificou-se aumento na frequência das precipitações mais intensas, evidenciado nas últimas décadas do século XX, mesmo em casos em que os períodos secos também se tornaram mais prolongados, como na ltália. 
Tabela 1 Resumo de Estudos Referenciais Acerca do Aumento das Precipitações como Resultado das Mudanças Climáticas Previstas

\begin{tabular}{|c|c|c|c|}
\hline AUTORIA & ANO & MÉTODOS & CONCLUSÕES \\
\hline $\begin{array}{l}\text { DEL GENIO; } \\
\text { LACIS; } \\
\text { RUEDY }\end{array}$ & 1991 & $\begin{array}{l}\text { Simulações com o General } \\
\text { Circulation Model (GCM) } \\
\text { - modelo matemático da } \\
\text { atmosfera terrestre. }\end{array}$ & $\begin{array}{l}\text { A cada grau }\left({ }^{\circ} \mathrm{C}\right) \text { a mais na temperatura } \\
\text { média do planeta há aumento de } 7 \% \text { na } \\
\text { umidade atmosférica, devendo intensificar } \\
\text { as precipitações na escada global. }\end{array}$ \\
\hline FREl et al. & 1998 & $\begin{array}{l}\text { Simulações do continente } \\
\text { europeu com modelos } \\
\text { climáticos globais, } \\
\text { considerando cenário } \\
\text { atmosférico mais quente e } \\
\text { úmido. }\end{array}$ & $\begin{array}{l}\text { A elevação de } 2^{\circ} \mathrm{C} \text { na temperatura média } \\
\text { do planeta ocasionará aumento de mais } \\
\text { de } 20 \% \text { na frequência de eventos de chuva } \\
\text { intensa (>30mm/dia). Os resultados são } \\
\text { válidos para latitudes médias }\left(30^{\circ} \text { a } 55^{\circ} \mathrm{N}\right. \\
\text { ou S) e regiões costeiras. }\end{array}$ \\
\hline $\begin{array}{l}\text { EMORI; } \\
\text { BROWN }\end{array}$ & 2005 & $\begin{array}{l}\text { Simulações em } \\
\text { modelos climáticos } \\
\text { globais dinâmicos e } \\
\text { termodinâmicos. }\end{array}$ & $\begin{array}{l}\text { Nas latitudes médias e altas, haverá } \\
\text { aumento nas precipitações médias anuais } \\
\text { e na frequência dos eventos extremos de } \\
\text { chuva. }\end{array}$ \\
\hline $\begin{array}{l}\text { CUBASCH } \\
\text { et al. } \\
\text { Terceira } \\
\text { Avaliação do } \\
\text { IPCC }\end{array}$ & 2001 & \multirow{2}{*}{$\begin{array}{l}\text { Hierarquia de modelos } \\
\text { climáticos globais, } \\
\text { considerando diversos } \\
\text { cenários quanto à emissão } \\
\text { de GEE. Para as projeções } \\
\text { quanto às precipitações } \\
\text { de } 2000 \text { a } 2100 \text {, foram } \\
\text { definidos três cenários } \\
\text { futuros sem mitigação das } \\
\text { emissões. Os modelos } \\
\text { tiveram também como } \\
\text { input os dados das } \\
\text { emissões de } 1900 \text { a } 2000 . \\
\text { (CUBASCH et al., p 538; } \\
\text { MEEHL et al., p. } 755 \text { ). }\end{array}$} & $\begin{array}{l}\text { Aumento da intensidade das precipitações } \\
\text { e dos eventos extremos de chuva, com } \\
\text { diminuição do período de retorno desses } \\
\text { eventos em quase todo o planeta (p. } 572 \text { - } \\
573 \text { ). Reconhece, contudo, a necessidade } \\
\text { de simulações regionais para obter } \\
\text { resultados específicos para cada lugar. }\end{array}$ \\
\hline $\begin{array}{l}\text { MEEHL et al. } \\
\text { Quarta } \\
\text { Avaliação do } \\
\text { IPCC }\end{array}$ & 2007 & & $\begin{array}{l}\text { Projeções para o aumento da intensidade } \\
\text { das precipitações, particularmente em } \\
\text { latitudes tropicais e altas, para onde também } \\
\text { se prevê maior frequência nos eventos } \\
\text { extremos de chuva (p. 750). No geral, a } \\
\text { precipitação média deve aumentar } 5 \% \text { sobre } \\
\text { os continentes, mas há variações espaciais e } \\
\text { sazonais específicas de cada modelo. }\end{array}$ \\
\hline
\end{tabular}

Fontes: Ver tabela.

Considerando esse aumento nos eventos extremos de chuva, apesar das incertezas quanto à magnitude e às variações regionais das mudanças climáticas, algumas cidades e regiões já avaliaram os possíveis impactos das precipitações mais intensas em seus sistemas de drenagem urbana (figura 1). Diante das imprecisões quanto à quantificação do aumento previsto, um dos estudos analisados, considerado pioneiro no campo, simulou as implicações sobre a infraestrutura de drenagem atribuindo diferentes porcentagens para a intensificação das chuvas: de $10 \%, 20 \%$ e $30 \%$. (NIEMCZYNOWICZ, 1989). 
Mesmo em cenários distintos, esses estudos apresentam alguns pontos em comum quanto aos impactos das chuvas mais intensas e frequentes sobre a drenagem urbana, a saber:

- o aumento das áreas impermeáveis nas cidades, associado ao crescimento urbano, deverá contribuir para agravar os riscos de enchentes e os impactos ambientais sobre os rios e riachos, destinos finais dos escoamentos superficiais;

- os custos para adaptação das infraestruturas de drenagem a chuvas mais intensas e frequentes, caso se faça a opção pela ampliação da rede por técnicas convencionais, serão elevados; a separação entre os sistemas de esgotamento e drenagem é sugerida como solução mais sustentável para mitigar os impactos, mas também mais onerosa. (FARAM et al., 2010);

- o uso de tubulações de maior diâmetro para suportar vazões maiores poderá diminuir a velocidade de escoamento nos períodos secos e causar problemas de acúmulos de sedimentos;

- caso a intensidade e frequência das chuvas fortes continuem a aumentar, as ampliações nos sistemas de drenagem poderão demandar novas intervenções no futuro, significando mais gastos e novas obras.

\section{LONDRES - Wilby, R. L. 2007}

O número de propriedades sob risco de enchentes intraurbanas, estimado atualmente em $80 \mathrm{mil}$, podera quadruplicar, e os prejuizos anuais poderāo atingir 15 bilhöes de libras em 2080. Os gastos com saúde pública tambéntaumentarão devido a diarreias e doenças respiratórias associadas a enchentes.

\section{Clinew the \\ 4

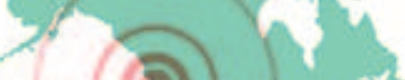 \\ CANADÁ. Denault et al. 2006}

Apesar de jâ haver uma tendència de aumento na intensidade das chuvas, prevista para continuarem décadas futuras, o sistema de drenagem da Grande Vancouver nào deverá sofrer grandes impactos, caso haja um planejamento a longo praze para ampliar a capacidade da infraestrutura existente, sem custos proibitivos. A preocupação do estudo refere-se ao aumento da impermeabilidade nas àreas urbanas e aos danos ambientais aos riachos e rios resultantes do crescimento urbano. Sugere-se, entăo, o uso de técnicas de manejo das águas de chuva para mitigar esses impactos.
SUÉCIA - Niemczynowicz, J. 1989

0 aumento da intensidade das chuvas em 20 a $30 \%$ causarà problemas significativos de enchentes na cídade. Os custos para evitá-los, através da ampliaçầo da rede de esgoto e drenagem e construçăo de novas estaçổes de tratamento, serJ̃o muitoaltos. Técnicas de retenção e infiltraçăo poderào ser alternativas para aliviar a infcaestrutura existente e criar um estoque de volume a ser retido.

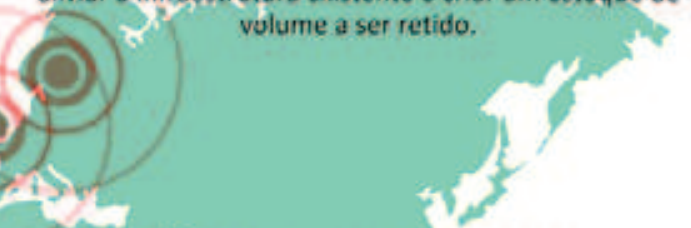

ÁFRICA - Douglas et al. 2008

Desde 1995, várias cidades africanas tềm enfrentado enchentes extremas e as projeçoes futuras sào de que 1 a intensidade e frequência dos temporais deverdo aumentar. A pobreza, as infraestruturas de drenagem e esgotamento precárias, a ocupaçào de varzeas e o crescimento desordenado das cidades deverào agravar o problema das enchentes futuras, causando grandes danos materiais, problemas de saúde pública e perdas humanas.

Figura 1 Estudos em escala local ou regional que relacionam a maior intensidade nas precipitações com os impactos na infraestrutura urbana de drenagem.

Foto: Newton Becker - 2011

Fontes: Ver figura. 
Além dos impactos previstos, os estudos analisados, reforçados por outras pesquisas (FARAM et al., 2010; MAILHOT; DUCHESNE, 2010; SCHOLZ; YANG, 2010; WATERS et al., 2003), reconhecem a importância do planejamento urbano a longo prazo, a ser pensado, desde já, como estratégia fundamental para evitar maiores transtornos quanto à drenagem num futuro não muito distante. Sugerem, também, ao considerar os investimentos elevados - necessários para adaptar os sistemas convencionais aos cenários previstos -, que técnicas alternativas e mais naturalizadas de condução, retenção e infiltração das águas de chuva podem ser empregadas como soluções complementares para mitigar o problema.

\section{MELHORES PRÁTICAS DE MANEJO DAS ÁGUAS DE CHUVA COMO ESTRATÉGIA MITIGADORA DOS IMPACTOS SOBRE A INFRAESTRUTURA DE DRENAGEM}

De todos os usos que resultam em impactos sobre as bacias e águas superficiais, a impermeabilização do solo, associada à urbanização, é de longe a mais significativa, provocando distúrbios em toda cadeia de processos ecológicos. Segundo a revista Science (Cohen, 2003), em 2030, a população urbana deve passar de 75\% para $83 \%$ nos países desenvolvidos e de $40 \%$ para $56 \%$ nos países em desenvolvimento, indicando que as superfícies impermeáveis serão expandidas e, com elas, os impactos ambientais. Consequentemente, os escoamentos superficiais também aumentarão e, com a intensificação prevista nas precipitações, a infraestrutura de drenagem nas cidades será submetida a uma demanda sem precedentes.

Nesse contexto, soluções de MPM das águas de chuva como alternativas de Desenvolvimento de Baixo Impacto (LID - Low Impact Development) ou técnicas compensatórias de drenagem pluvial $^{4}$ poderão mitigar o problema e garantir maior longevidade aos sistemas de drenagem, além de melhorar a qualidade da água que chega aos riachos e rios urbanos. (CITY OF PORTLAND, 2009).

Segundo Nascimento e Baptista (2009), desde 1970, as MPM têm sido utilizadas como abordagem alternativa para tratar as questões de quantidade e qualidade dos escoamentos superficiais. Com a inserção de medidas de controle da polvição difusa ao Clean Water Act, pelo Congresso americano, em 1987, as MPM passaram a ser ferramentas indispensáveis para drenagem (HA; STENSTROM, 2008), sendo utilizadas de forma extensiva pelos EUA nos anos 1990 (ROESNER, 2001) e, posteriormente, ganhando adeptos em todo o mundo. (HA; STENSTROM, 2008).

Atualmente, cidades norte-americanas, como Portland (OR), na região noroeste, apresentam aparatos técnico e legislativo que garantem o caráter compulsório dessas técnicas de manejo das águas de chuva. (CITY OF PORTLAND, 2009). No tratamento dos espaços abertos, públicos ou privados, essas soluções diminuem o volume do

4 Essas técnicas são ditas compensatórias por terem como objetivo minorar os impactos da urbanização sobre o ciclo hidrológico. (NASCIMENTO; BAPTISTA, 2009). 
escoamento superficial, aumentam a infiltração e removem os polventes difusos antes que alcancem os recursos hídricos. (DIETZ, 2007).

Baseados nos princípios de biorretenção, em que a abordagem da drenagem procura mimetizar as condições hidrológicas pré-urbanas através do uso de técnicas mais naturalizadas de retenção, infiltração e evapotranspiração (DEBUSK, 201 1), as MPM das águas de chuva fazem uso de diversas tipologias, algumas das quais recomendas pelo Manual de Manejo de Água de Chuva de Portland (CITY OF PORTLAND, 2009) e por Cormier e Pellegrino (2008). São elas:

- jardins de chuva: são depressões topográficas que recebem o escoamento da água pluvial; o solo, tratado com compostos e demais insumos, como pedriscos, que aumentam sua porosidade, age como uma esponja a sugar a água, enquanto microrganismos e bactérias removem os polventes difusos trazidos pelo escoamento superficial; a adição de plantas aumenta a evapotranspiração e a remoção de nutrientes (figura 2);

- biovaletas: são semelhantes aos jardins de chuva, mas geralmente se referem a depressões lineares preenchidas com vegetação, solo e demais elementos filtrantes, que processam uma limpeza da água da chuva, ao mesmo tempo em que aumentam seu tempo de escoamento, dirigindo este para os jardins de chuva (figura 3);

- canteiros pluviais: são basicamente jardins de chuva que foram compactados em pequenos espaços urbanos; um canteiro pode contar, além de sua capacidade de infiltração, com um extravasador, ou, em exemplos sem infiltração, só com a evaporação, a evapotranspiração e o transbordamento (figura 4);

- lagoas pluviais: funcionam como bacias de retenção e recebem o escoamento superficial por drenagens naturais ou tradicionais; uma parte da água pluvial captada permanece retida entre os eventos de precipitação das chuvas; dessa forma, essas tipologias paisagísticas acabam se caracterizando como um alagado construído, mas não destinado a receber efluentes de esgotos domésticos ou industriais (figura 5).

A eficiência desses elementos de biorretenção quanto à diminuição do volume de escoamento e de alguns dos seus principais constituintes problemáticos - segundo Roesner (2001), sólidos em suspensão, nutrientes (P e N), metais pesados (Cu, Pb e Zn) e bactérias fecais (E. coli) - tem sido comprovada por estudos e casos práticos. Debusk et al. (2011) verificaram que biovaletas associadas a estacionamentos reduzem o volume do escoamento das áreas impermeáveis em $97 \%$ a $99 \%$ e diminuem a massa de sedimentos, nitrogênio total e fósforo total em $99 \%$. 


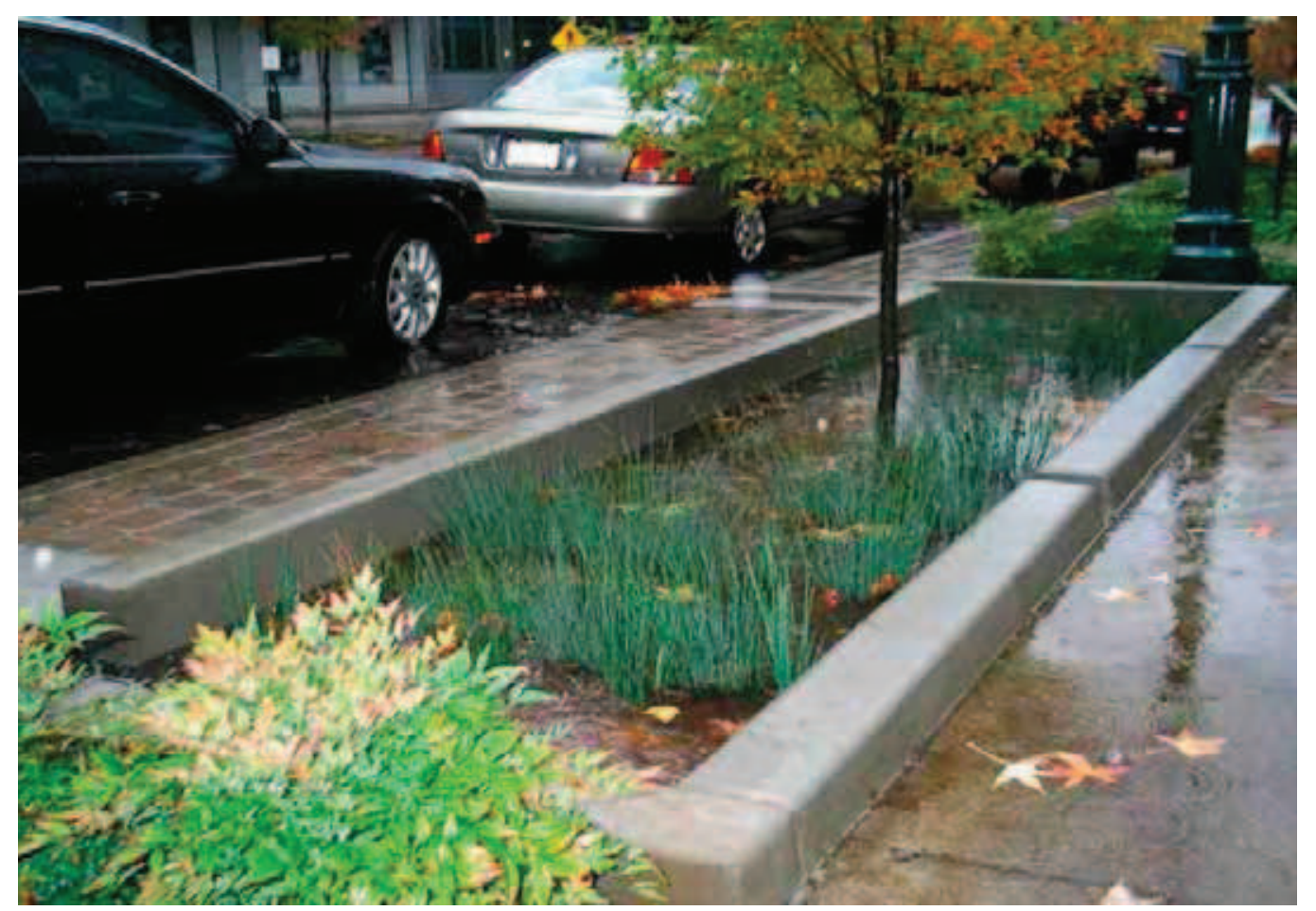

Figura 2 12th Green Street, em Portland, Oregon (USA). Foto: Nate Cormier.

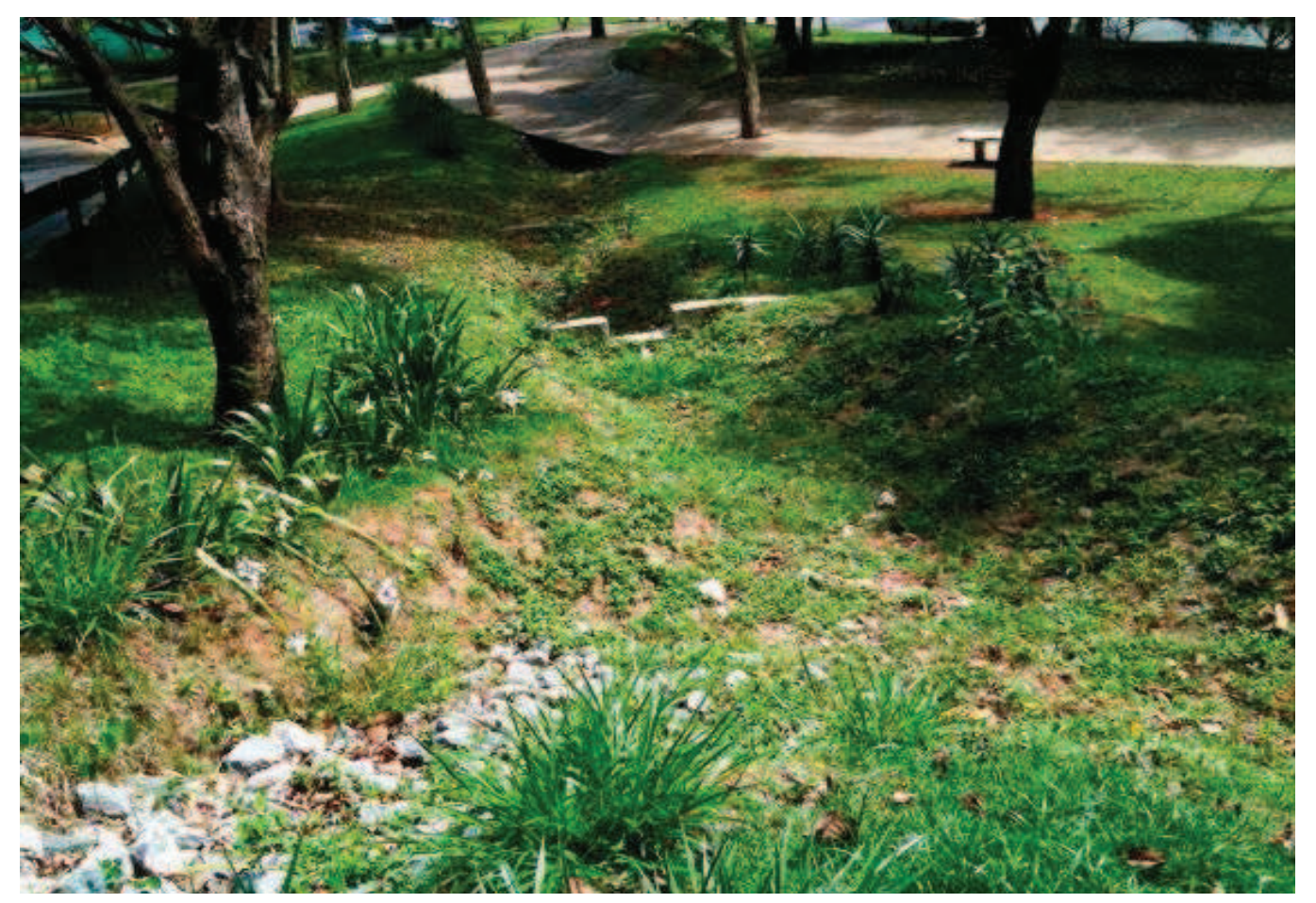

Figura 3 Praça das Corujas, Vila Madalena, São Paulo (SP). Foto: Paulo Pellegrino. 


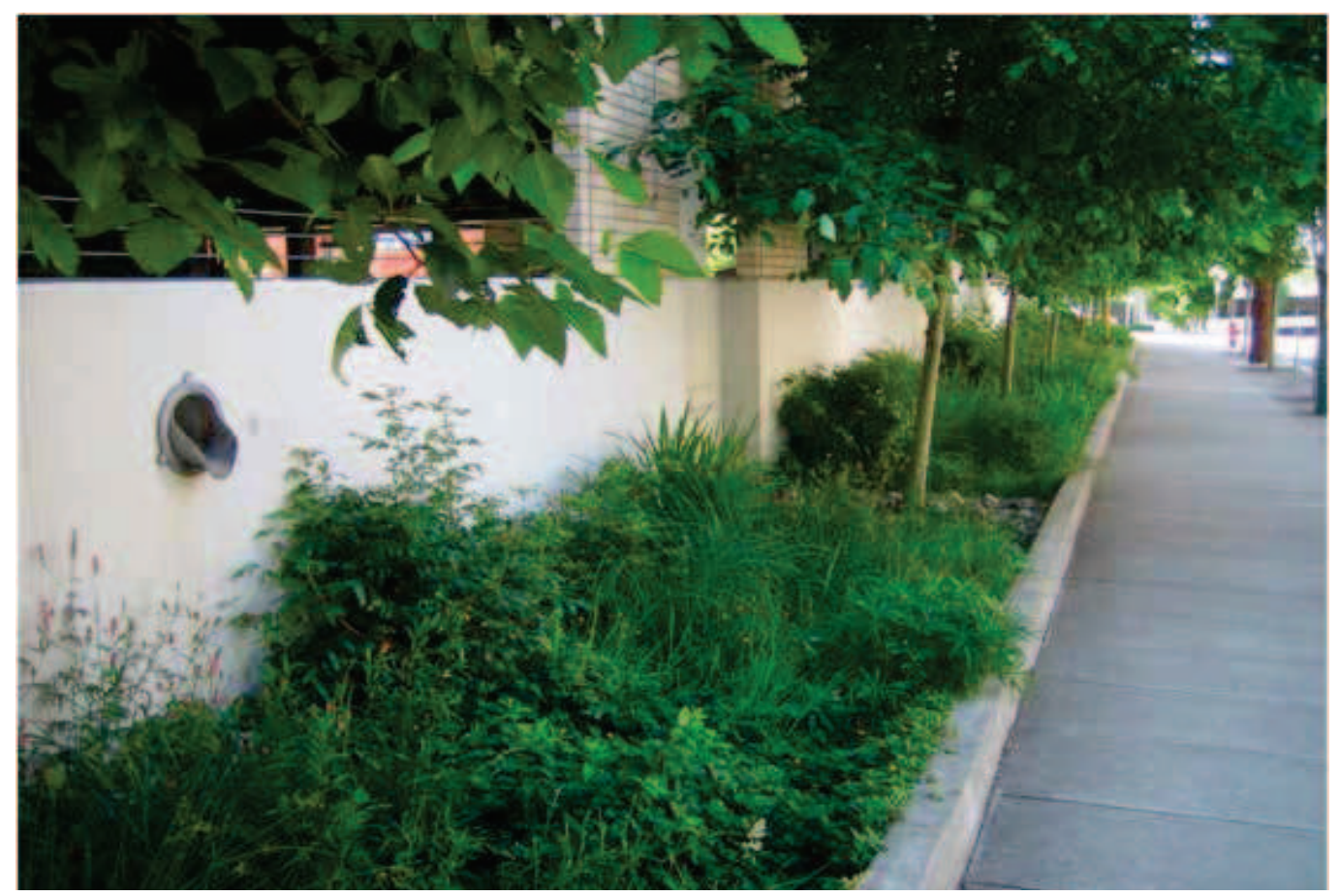

Figura 4 Liberty Center Parking Garage. Portland, Oregon (USA).

Foto: Nate Cormier.

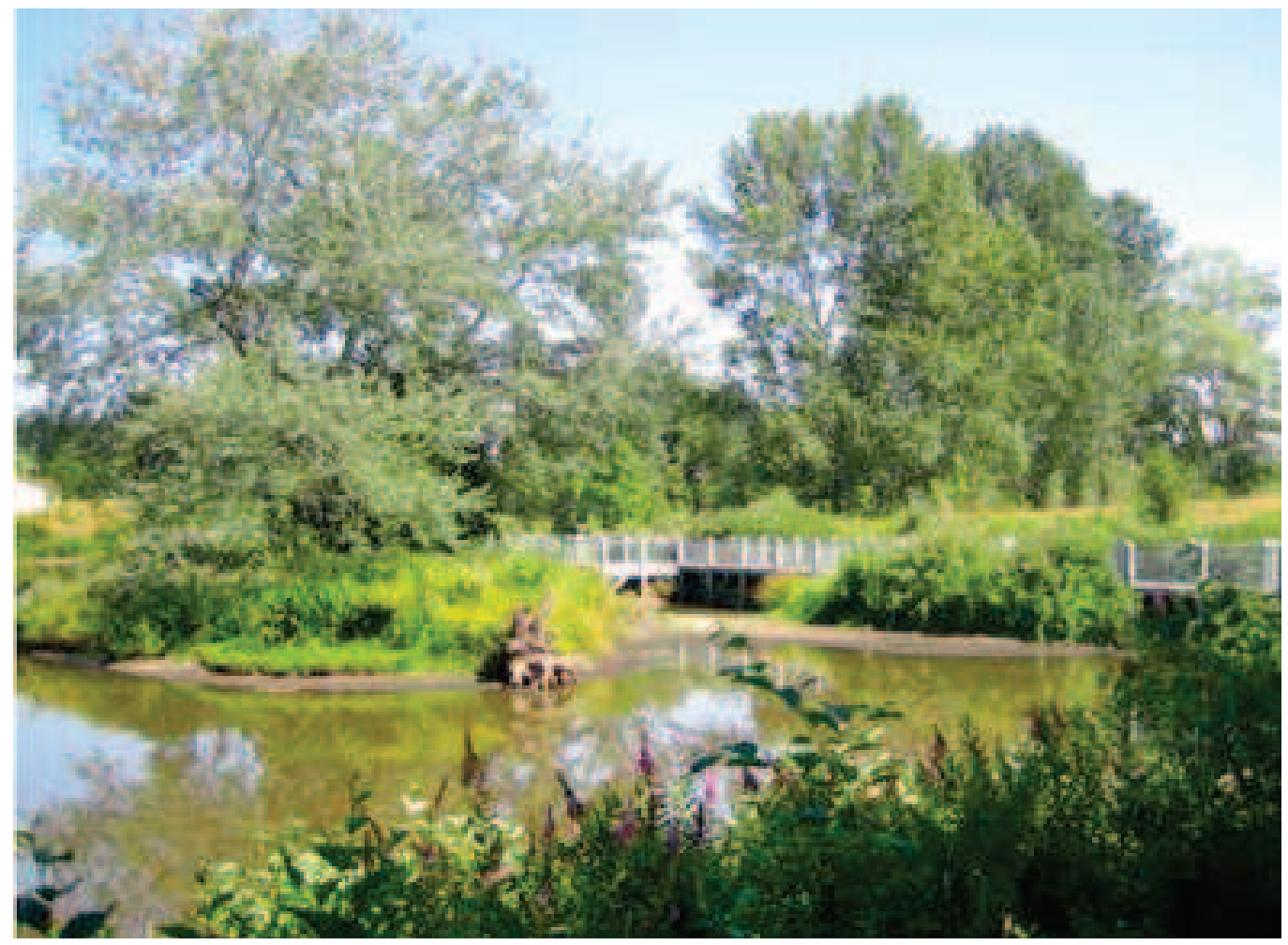

Figura 5 Meadowbrook Pond, em Seattle, Washington (USA). Foto: Nate Cormier - 2010. 
Weiss et al. (2007) investigaram diversos modelos de biorretenção e obtiveram reduções de $85 \%$ dos sólidos em suspensão e de $72 \%$ do fósforo total em jardins de chuva. Dietz (2007) comprovou reduções nas concentrações de metais (Cu, Pb e Zn) acima de $90 \%$, tanto em testes de protótipos em laboratórios como em campo, e enfatizou que as técnicas LID de manejo das águas de chuva são práticas relativamente novas, ainda em evolução, mas apresentam grande potencial para mitigar os problemas do desenvolvimento urbano sobre os corpos hídricos. Contudo, lembra que a eficiência dos elementos de biorrenteção pode ser comprometida por aspectos de projeto e execução inadequados, como uso de substratos argilosos que impedem a infiltração e instalação em terrenos muito inclinados ou com leito de rochas muito superficial.

\section{ESTUDO DE CASO: RESERVATÓRIOS DE DETENÇÃO DO BOM PASTOR - SANTO ANDRÉ (SP)}

\subsection{MUDANÇAS CLIMÁTICAS E O AUMENTO DAS CHUVAS EXTREMAS NO ESTADO DE SÃO PAULO}

Simulações em modelos climáticos para a América do Sul, considerando os cenários A2 e B2 quanto às emissões de GEE (IPCC, 2007), observaram algumas mudanças climáticas como consequência do aquecimento global, entre as quais o aumento significativo nas precipitações extremas. Grimm (2011) salienta a diferença de resultados entre os modelos utilizados e as oscilações climáticas interanuais causadas pelo El Niño como possíveis indicadores de incertezas científicas. Contudo, para a porção sudeste da América do Sul, onde se localiza o Estado de São Paulo, as coincidências entre as simulações reforçam a possibilidade do aumento na intensidade e frequência de chuvas mais fortes, principalmente no verão, o que também é verificado no estudo de Marengo et al. (2009).

Projeções realizadas pelo Instituto Nacional de Pesquisas Espaciais (INPE) para a Região Metropolitana de São Paulo (RMSP), que já sofre com enchentes no verão, indicam um aumento provável no número de dias com fortes chuvas até o final do século. (NOBRE et al., 2009).

Estudos preliminares do INPE sugerem que, entre 2070 e 2100 , uma elevação média na temperatura da região, de $2^{\circ} \mathrm{C}$ a $3^{\circ} \mathrm{C}$, poderá dobrar o número de dias com chuvas intensas (acima de 10 milímetros) na capital paulista.

Além das projeções futuras, a análise do padrão das chuvas na região sudeste da América do Sul por Re e Barros (2009), no período de 1959 a 2002, comprovou uma tendência de aumento nas precipitações anuais e na frequência dos eventos mais fortes, de 50 a 150 milímetros, nas últimas décadas. Um estudo específico para o Estado de São Paulo (DUFEK; AMBRIZZI, 2008), de 1950 a 1999, identificou um incremento significativo tanto nos eventos extremos de precipitações ${ }^{5}$ como no núme-

\footnotetext{
$5 \quad$ Chuvas com índices acima do percentil 95.
} 
ro de dias com chuvas acima de 20 milímetros e nas precipitações máximas em períodos de cinco dias. O INPE, ao analisar as precipitações da RMSP de 1933 a 2009, também verificou crescimento no número de eventos de forte precipitação (figura 6): acima de $30 \mathrm{~mm} /$ dia, valor que tem potencial para causar enchentes e inundações graves. (NOBRE et al., 2009). Há consenso, portanto, quanto ao aumento no padrão de frequência das chuvas mais intensas no Estado de São Paulo e na RMSP.

Marengo et al. (2009), contudo, afirmam ser impossível atribuir com certeza absoluta a ocorrência de eventos extremos às mudanças climáticas antropogênicas devido à natureza probabilística dos mesmos. "Existe sempre a chance de que esses eventos sejam resultado da variabilidade climática natural [...]", enfatizam os autores.

Os relatórios do IPCC - Intergovernmental Panel on Climate Change (CUBASCH et al., 2001; MEEHL et al., 2007; IPCC, 2007), por sua vez, empregam expressões como provavelmente, muito provavelmente e extremamente provável para qualificar as projeções das mudanças climáticas e a relação destas com o aumento nas emissões de GEE. Mesmo diante das incertezas, tais relatórios enfatizam a importância de assumir um posicionamento preventivo quanto às possíveis mudanças climáticas, que deve incluir as seguintes estratégias: utilização de modelos para compreender as tendências regionais e locais dos cenários futuros quanto ao clima; mitigação das emissões de GEE; adaptação aos impactos ambientais previstos.

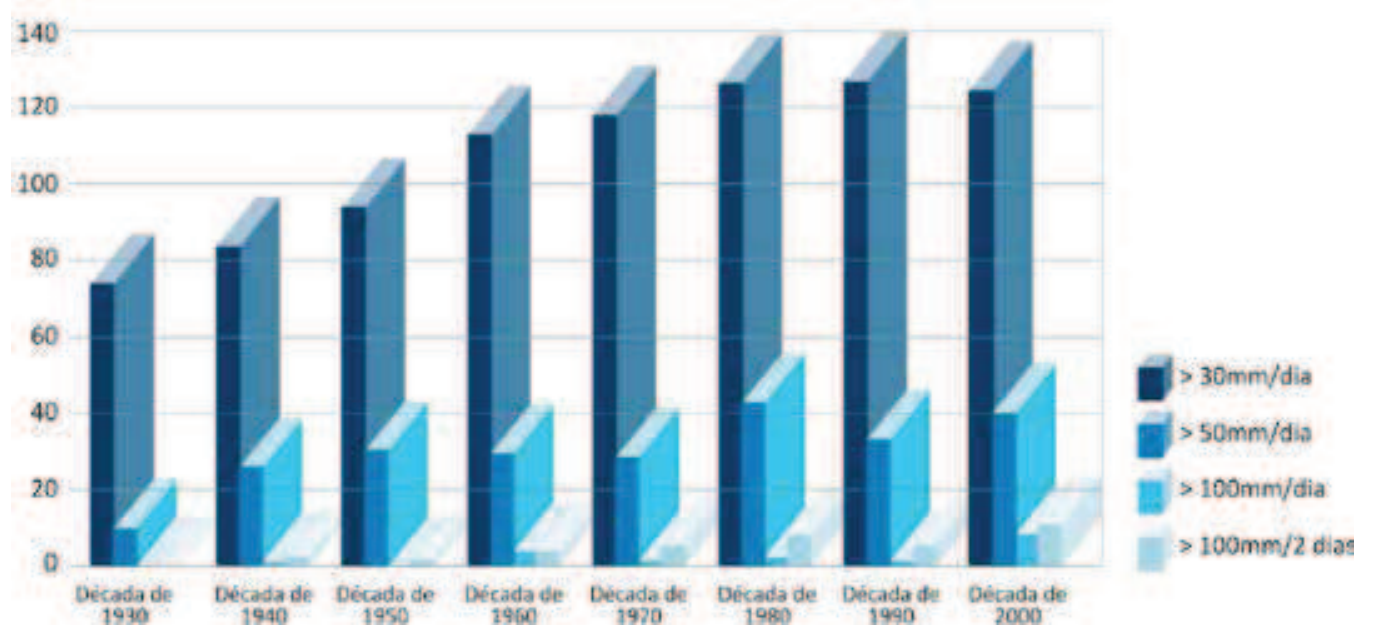

Figura 6 Eventos de chuvas intensas em São Paulo (SP). Fonte: INPE - 2009.

\subsection{AS SOLUÇÕES ADOTADAS PARA O CONTROLE PLUVIAL NA GRANDE SÃO PAULO}

Diante do quadro atual de crescimento urbano desordenado e chuvas intensas na RMSP, que tende a se agravar, as soluções convencionais se impõem ainda como o modelo dominante. Por terem alcançado eficiência comprovada em condições críticas, adquiriram respeitabilidade técnica através de memórias de cálculos, obras 
executadas e resultados que puderam ser previstos e calculados de forma precisa. As organizações responsáveis e os construtores de infraestrutura fazem, então, sua opção pelo sistema de drenagem que escoa as águas de chuva com rapidez para os rios principais, sem nenhum tratamento prévio, o que vem sobrecarregando a própria infraestrutura e a qualidade dos córregos e rios como destino final.

Quanto ao controle pluvial, o emprego de reservatórios de detenção, conhecidos como piscinões, mostrou ser uma solução bastante eficaz no combate às enchentes em bacias hidrográficas urbanizadas da Grande São Paulo (figura 7). Por proporcionarem a redução das áreas alagadas após eventos de chuva, minimizam perdas materiais da população, problemas no trânsito e outras inúmeras questões relacionadas à incapacidade dos córregos de dar vazão ao volume de água que precisa ser drenado.

Diante da situação crítica da RMSP, o Plano de Macrodrenagem para a região, elaborado pelo Departamento de Águas e Energia Elétrica (DAEE), prevê a implementação de mais 134 piscinões na área urbana da bacia do Tietê até 2020, numa tentativa de simular hidraulicamente o papel das várzeas. Contudo, ao considerar o ciclo hidrológico e os processos naturais, sem falar nos impactos sociais e urbanos, essa estratégia tem se mostrado ineficiente. A questão é solucionada do ponto de vista hidráulico, porém, juntamente com as ondas de cheias, toda a polvição da bacia hidrográfica é escoada para os reservatórios, que detêm não apenas a água excedente, mas também lixo e assoreamento. Ocorrem, então, inúmeros inconvenientes para a operação e manutenção destes equipamentos, tais como problemas de obstrução de grades e bombas, aspecto desagradável e mau cheiro, que resultaram na rejeição desse tipo de estrutura pela população e vizinhança imediata.

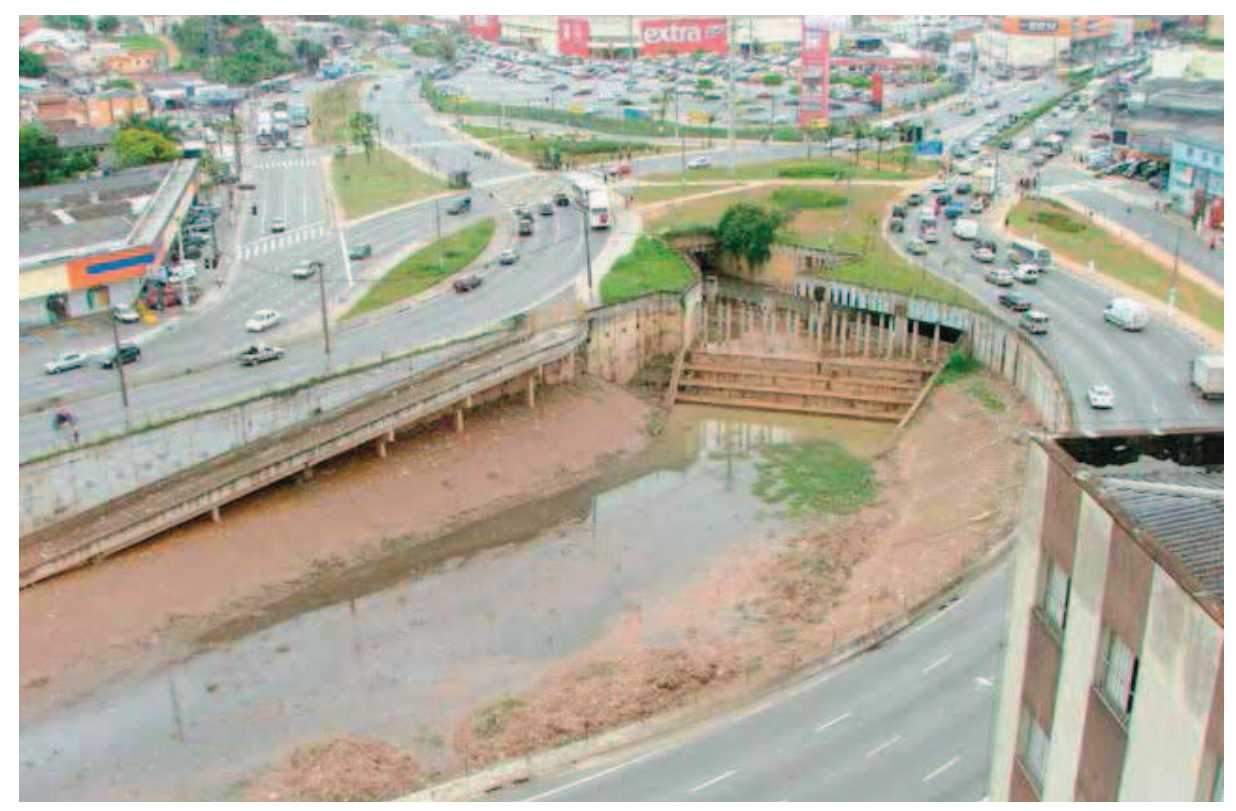

Figura 7 Piscinão Eliseu de Almeida, na Zona Leste de São Paulo (SP). Foto: Newton Becker. 


\section{A ÁREA DE ESTUDO}

A bacia elegida como estudo de caso está localizada no município de Santo André, RMSP (figura 8). Nesta bacia, com área de contribuição aproximada de 45 hectares, foram construídos, em 1991, os reservatórios de detenção do Bom Pastor, nome do bairro em que estão situados. Com volume de armazenamento total de $19.200 \mathrm{~m}^{3}$, os piscinões, inseridos no córrego Araçatuba, têm a função de deter o excedente de escoamento da bacia, evitando, além da enchente local, o transbordamento do Ribeirão dos Meninos, do qual o Araçatuba é afluente (figura 9).

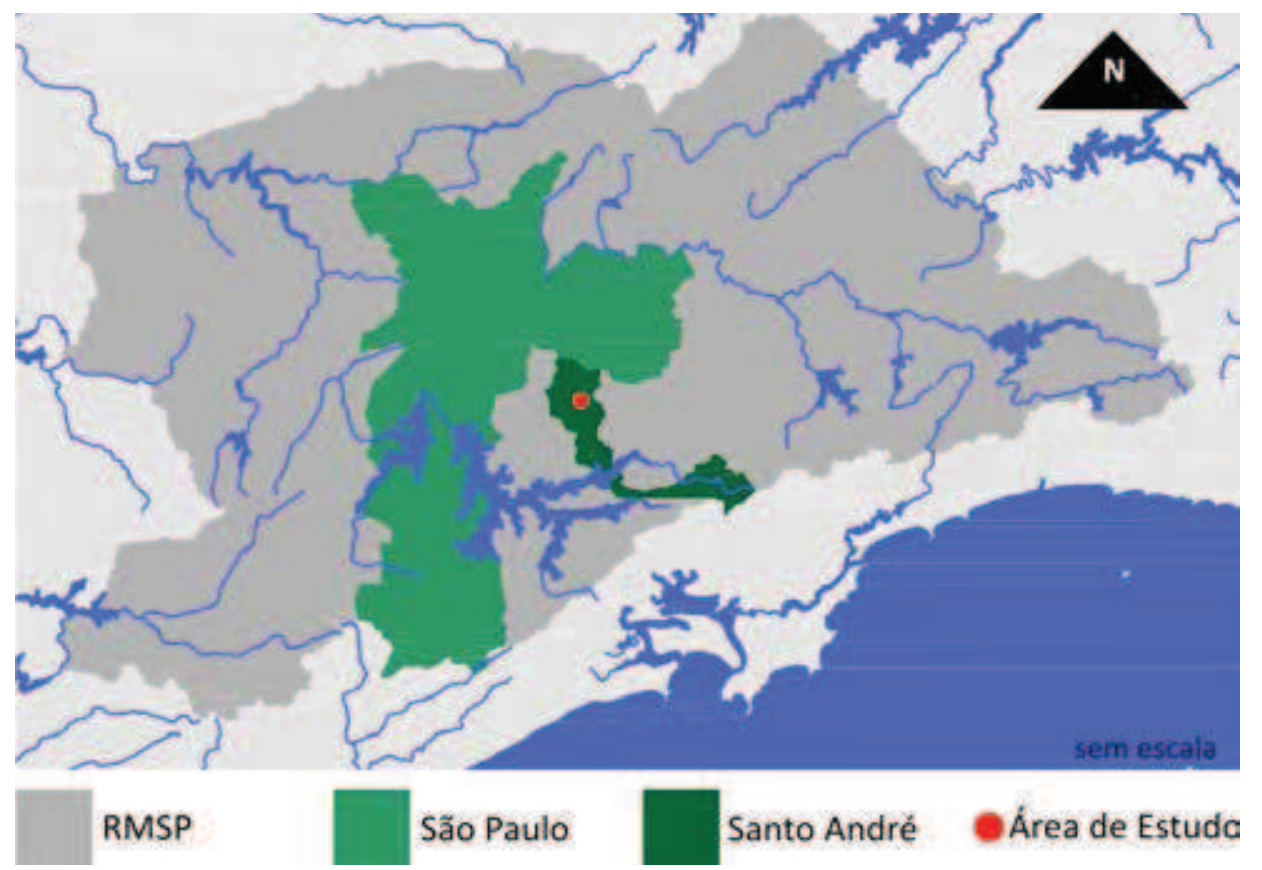

Figura 8 Localização da área de estudo. Fonte: Newton Becker.

Dimensionado para um período de retorno de apenas dois anos, verificou-se que o reservatório funciona muito bem quanto à função de contenção de cheias, e os moradores locais deixaram de ter suas casas ameaçadas pelas enchentes. Entretanto, registraram-se queixas da população da vizinhança devido à presença de mosquitos, mau cheiro e aspecto ruim. Além disso, análises da qualidade da água dos reservatórios realizadas pelo Departamento de Engenharia Hidráulica e Sanitária da Escola Politécnica da USP (PHD, 2008) evidenciaram a presença de polventes, tais como metais pesados, e indicadores de degradação ambiental, como concentrações elevadas de coliformes totais. Essas análises, realizadas em períodos secos e úmidos, comprovaram também que o quadro de polvição dos reservatórios e do córrego se agrava com os eventos de chuva, que conduzem os polventes difusos superficiais ao volume acumulado nos piscinões. 


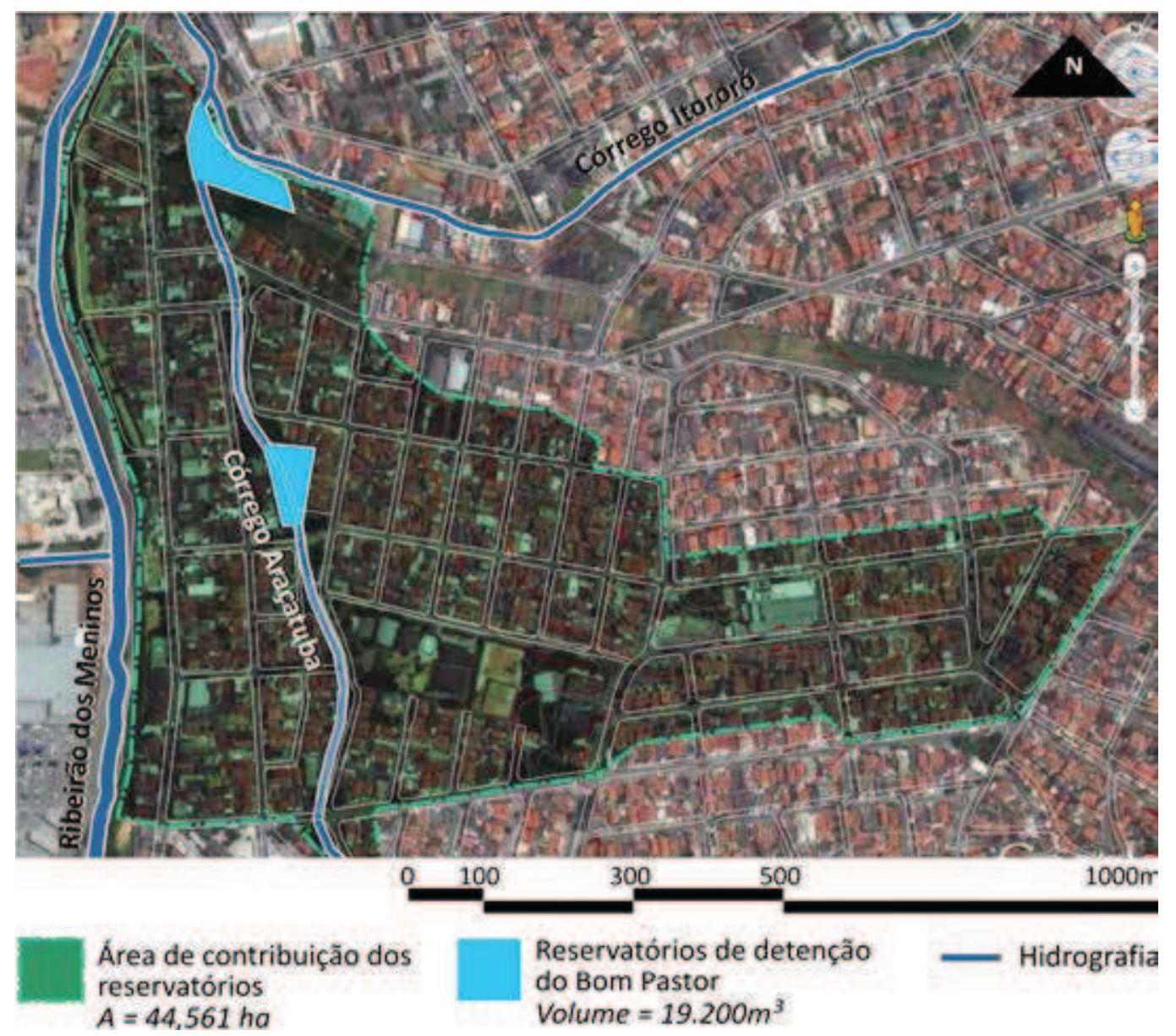

Figura 9 Localização da área de contribuição e dos reservatórios de detenção.

Fonte: Newton Becker.

\section{ANÁLISE DA CAPACIDADE DE RETENÇÃO DAS MELHORES PRÁTICAS DE MANEJO DAS ÁGUAS DE CHUVA}

Para quantificar o volume de retenção possível através do uso de técnicas de MPM das águas de chuva, elementos de biorretenção e pavimentos porosos foram espacializados em uma das ruas locais da área de contribuição dos reservatórios de detenção do Bom Pastor (figura 10). Com o estreitamento do leito carroçável e a aplicação dos princípios de amenização de tráfego (traffic calming), que definem ruas mais sinuosas e, portanto, reduzem a velocidade dos veículos, foram criados vazios para armazenar o escoamento pluvial nas subcamadas de brita e macadame hidráulico dos jardins de chuva, das biovaletas, dos passeios porosos padronizados e das faixas permeáveis de acesso aos lotes. 


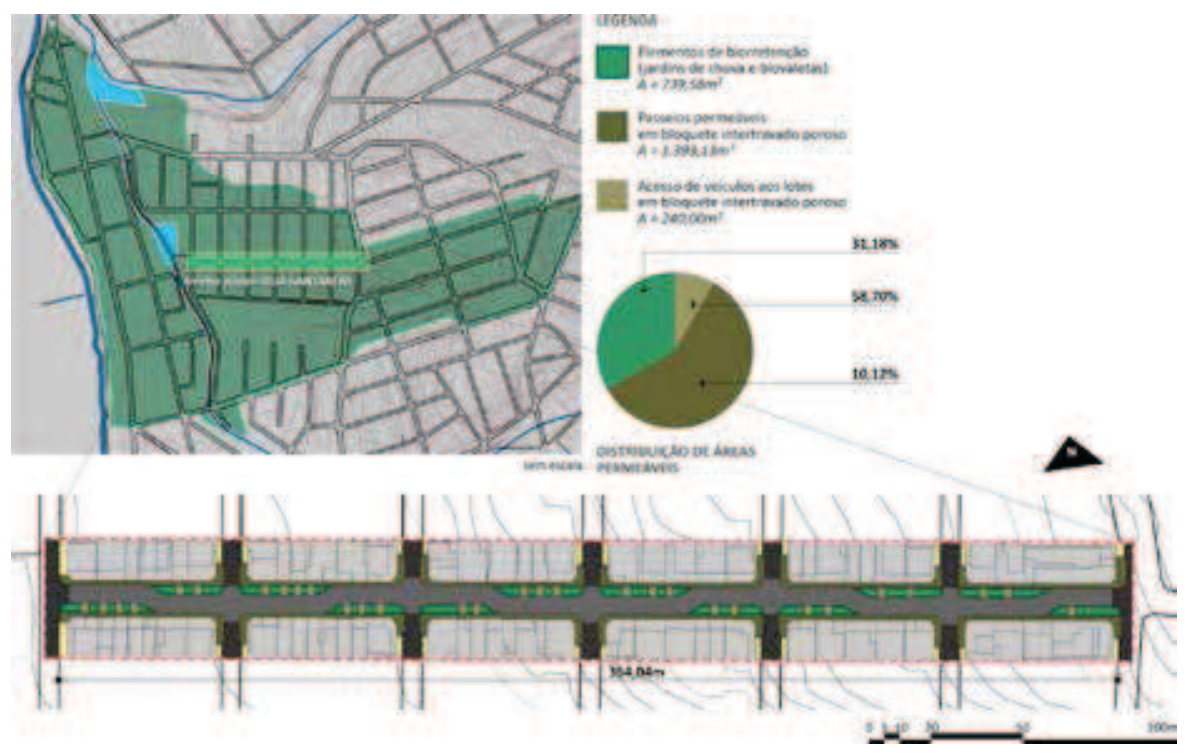

Figura 10 Distribuição dos elementos de biorretenção (biovaletas e jardins de chuva) e pavimentos porosos nos passeios e faixas de acesso aos lotes.

Fonte: Newton Becker - 2011

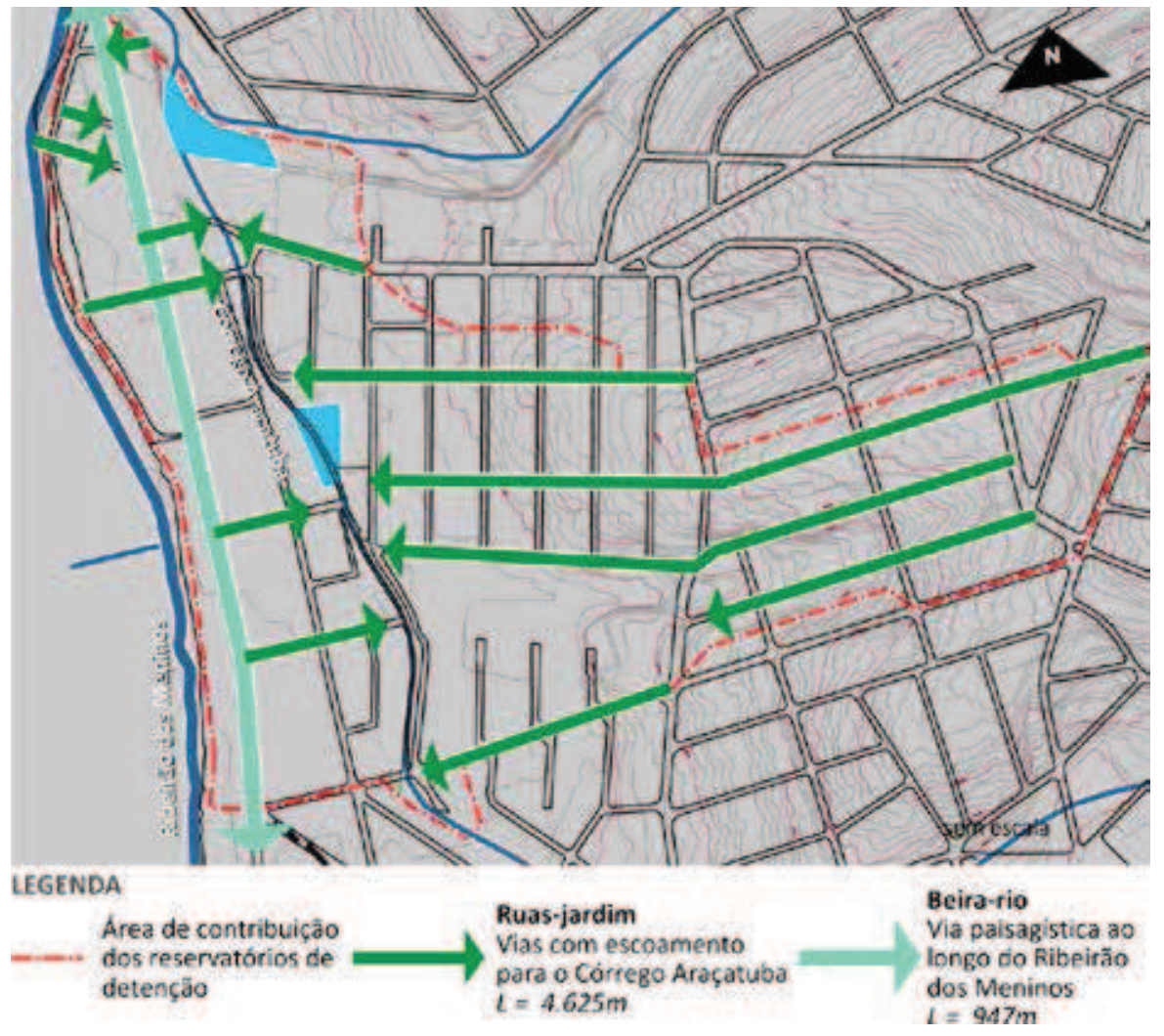

Figura 11 Replicação do tratamento viário e paisagístico da rua piloto para demais vias da área de contribuição. Fonte: Newton Becker - 2011 
Totalizadas as áreas desses elementos na rua piloto, as porcentagens identificadas dos mesmos foram replicadas para outras vias locais da área de contribuição, que também seriam requalificadas por um paisagismo de alto desempenho, configurando Ruas-jardins e uma Beira-rio ao longo do Ribeirão dos Meninos (figura 11). As ruas escolhidas para receber o tratamento proposto apresentam escoamento direcionado diretamente ao córrego Araçatuba, de acordo com a planialtimetria disponível.

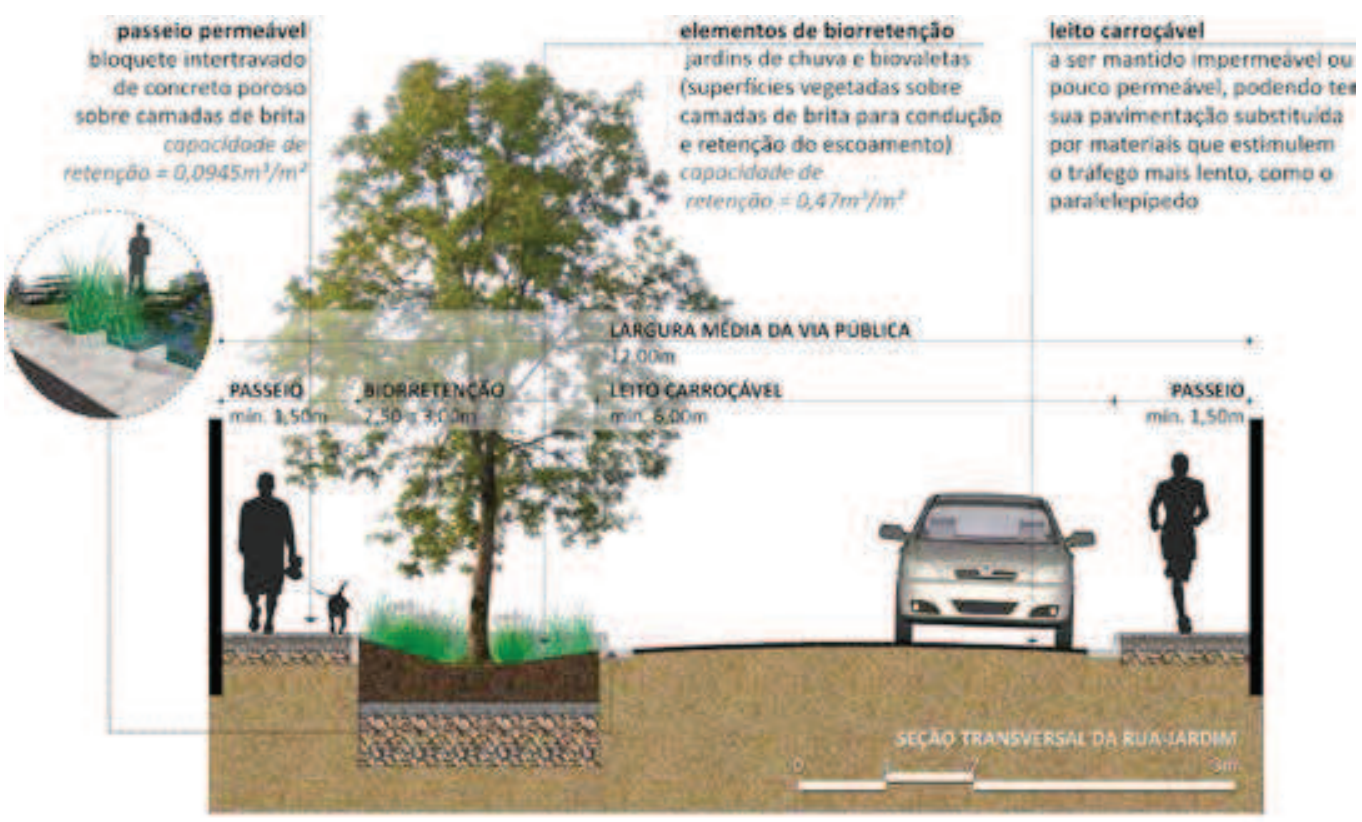

Figura 12 Seção transversal da Rua-jardim.

Fonte: Newton Becker.

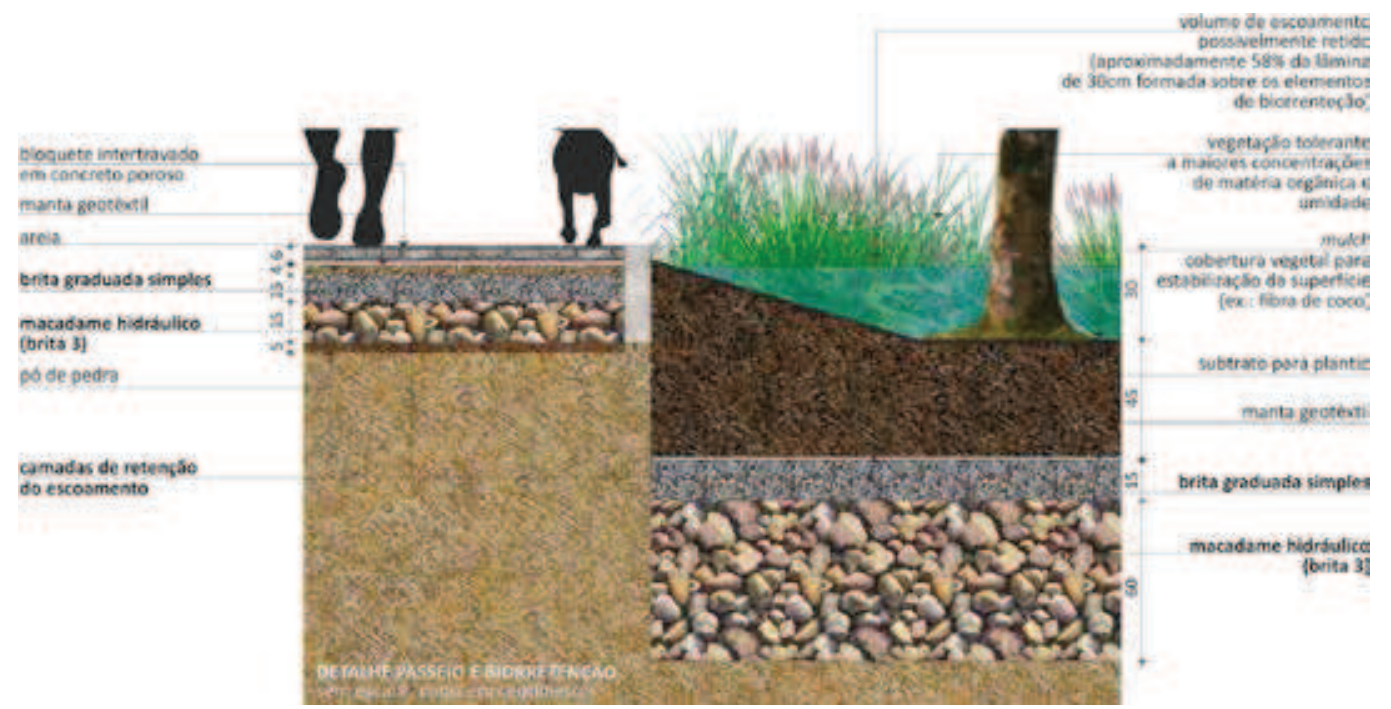

Figura 13 Detalhamento do passeio permeável do elemento de biorretenção.

Fonte: Newton Becker - 2011. 
Considerando o detalhamento das técnicas de biorretenção e pavimentos permeáveis (figuras 12 a 14), calculou-se, a partir da porosidade dos materiais construtivos utilizados, o volume de armazenamento/ $\mathrm{m}^{2}$ de cada elemento (tabelas 2 e 3). Sem levar em conta a infiltração no terreno natural e no substrato de plantio e a evapotranspiração a ser realizada pela vegetação de cobertura, chegou-se ao volume total de escoamento que poderá ser armazenado pelas técnicas de MPM das águas de chuva (tabela 4).

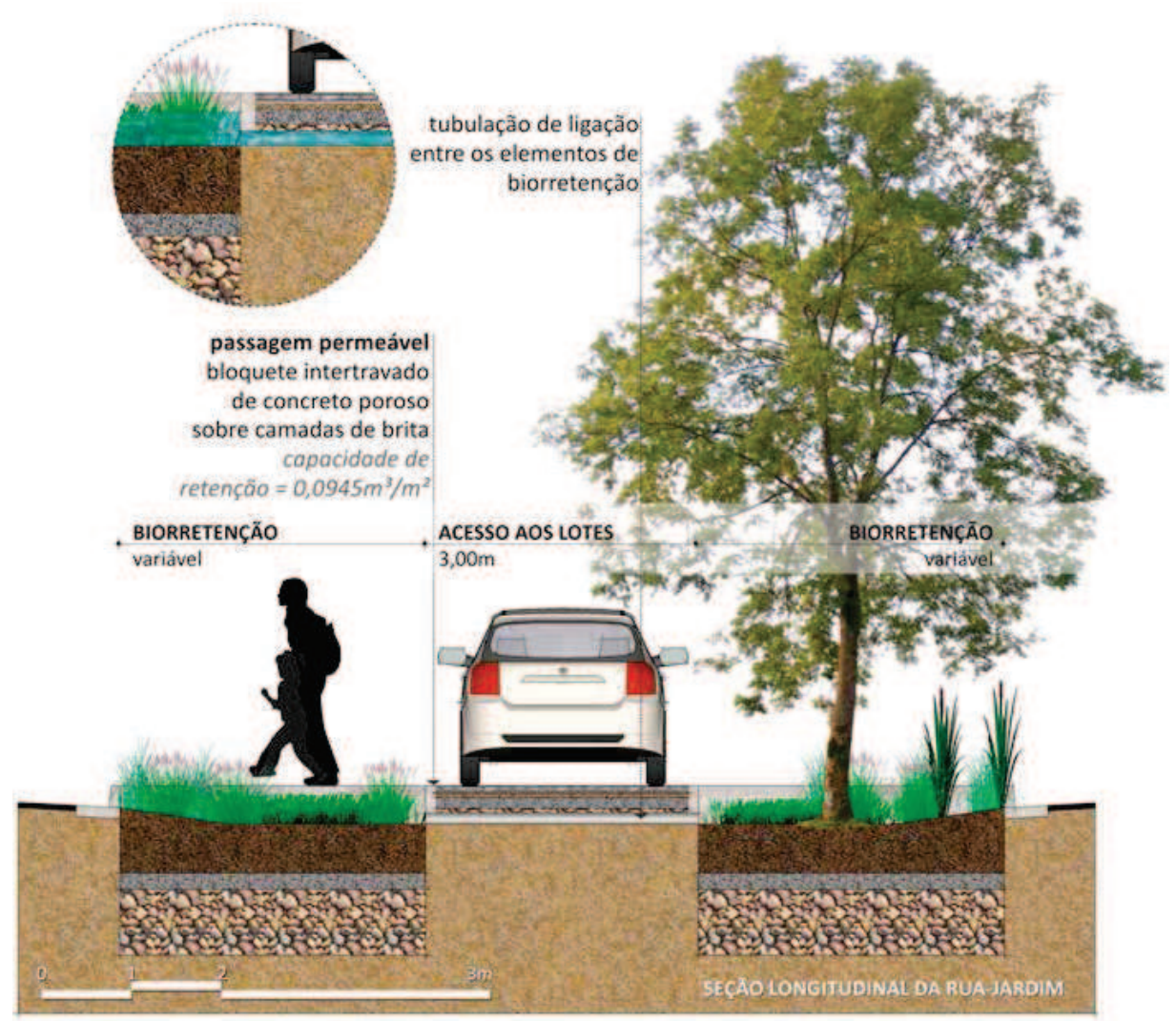

Figura 14 Seção longitudinal da Rua-jardim.

Fonte: Newton Becker - 2011.

Tabela 2 Cálculo da Porosidade dos Materiais Utilizados

parâmetros de cálculo para porosidade brita graduada brita 3 simples

\begin{tabular}{lcc}
\hline massa específica aparente $\left(\mathrm{g} / \mathrm{cm}^{3}\right) \cdot \gamma_{\mathrm{d}}$ & 2,169 & 1,491 \\
\hline densidade real dos grãos $\left(\mathrm{g} / \mathrm{cm}^{3}\right) \cdot \mathrm{Gs}_{\mathrm{s}}$ & 2,643 & 2,704 \\
\hline densidade real da água a $25^{\circ} \mathrm{C} \cdot \gamma_{\mathrm{w}}$ & 1,00 & 1,00 \\
\hline porosidade $(n)$ & 0,18 & 0,45
\end{tabular}

Fonte: Newton Becker - 2011. 
Tabela 3 Cálculo do Volume de Armazenamento $/ \mathrm{m}^{2}$ dos Elementos de Biorretenção e Pavimentos Permeáveis

\begin{tabular}{|c|c|c|c|c|c|}
\hline & h BGS & h 83 & $n_{\infty}$ & volume de retençāo/ $/ \mathrm{m}^{2}$ & $\begin{array}{l}\text { velume de reterglodos } \\
\text { camadas de bints }\end{array}$ \\
\hline biorretençà̀o & $15 \mathrm{~cm}$ & $60 \mathrm{~cm}$ & 0,396 & $0,296+0,174=0,47 \mathrm{~m}^{1}$ & , valume da lamini do esceamento \\
\hline passeios permeáveis & $15 \mathrm{~cm}$ & $15 \mathrm{~cm}$ & 0,315 & $0,0945 \mathrm{~m}^{1}$ & (sski da aimina de $30 \mathrm{~cm}$ ) \\
\hline passagens permeáveis & $15 \mathrm{~cm}$ & $15 \mathrm{~cm}$ & 0,315 & $0,0945 \mathrm{~m}^{\prime}$ & 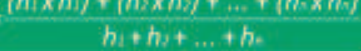 \\
\hline
\end{tabular}

Fonte: Newton Becker - 2011

Tabela 4 Cálculo do Volume Total de Armazenamento das Melhores Práticas de Manejo (MPM) na Área de Contribuição

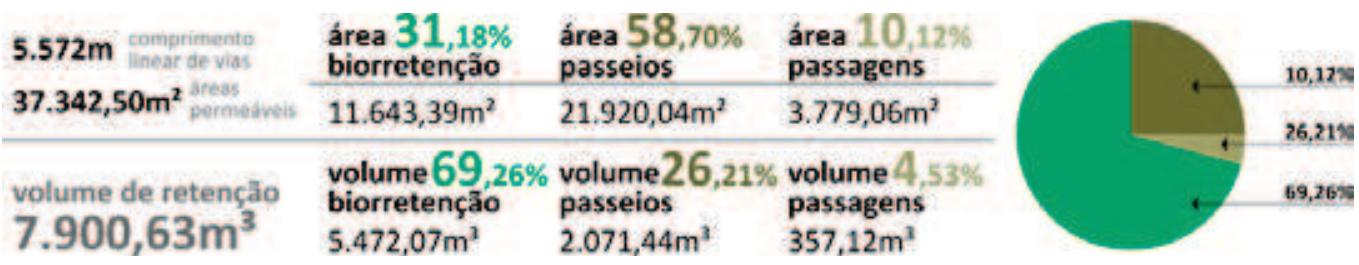

Fonte: Newton Becker - 2011 .

\section{CONCLUSÕES}

As mudanças climáticas implicam desafios diversos. No ambiente construído, a infraestrutura de drenagem e o controle pluvial já estão no seu limite de capacidade ou próximos a atingi-lo, com previsão de serem submetidos a maior demanda em breve, diante da intensificação dos eventos extremos de chuva. A necessidade de adaptação das cidades a esse cenário é iminente e soluções mais sustentáveis devem ser colocadas em prática para torná-las mais resilientes diante de um futuro incerto. A partir dos resultados obtidos na área de estudo, considerando os elementos permeáveis e de biorrenteção sugeridos, pode-se concluir que:

- as MPM das águas de chuva constituem alternativas tecnicamente viáveis para ampliar o estoque de volume de retenção em áreas urbanas, tendo em vista a tendência verificada no aumento da intensidade e frequência das precipitações extremas;

- essas soluções podem ser empregadas em complementação ou substituição às medidas convencionais de drenagem e controle pluvial, devendo-se levar em conta os comparativos de custos e de viabilidade entre as possibilidades técnicas na escolha da melhor tecnologia disponível a ser utilizada;

- o emprego das MPM das águas de chuva em novas urbanizações é menos oneroso e implica menos impactos do que no retrofit de áreas consolidadas, 
considerando que não há custos de demolição nem geração de resíduos da construção; em áreas ainda não ocupadas, as soluções de biorrenteção e pavimentos porosos podem garantir maior longevidade da infraestrutura de drenagem e evitar investimentos futuros com a implementação de reservatórios de detenção, cujos inconvenientes de manutenção e operacionalização já têm sido comprovados; as MPM, portanto, constituem ferramentas importantes a serem adotadas entre as políticas públicas que têm como estratégia a adaptação do ambiente urbano às mudanças climáticas;

- as técnicas de MPM são soluções relativamente novas quando comparadas às tecnologias convencionais de drenagem e controle pluvial, e, portanto, ainda estão em processo de evolução, apresentando imprecisões quanto aos resultados pretendidos, além de carência de informações quanto aos custos, à manutenção, operacionalização e Análise do Ciclo de Vida (ACV);

- por constituírem técnicas mais naturalizadas e mais adaptadas ao ciclo hidrológico pré-urbano, essas soluções apresentam menos impactos sobre o ambiente construído, contudo, a sua eficiência técnica depende das condições locais, que podem, inclusive, limitar a sua utilização, tais como lençol freático pouco profundo, leito de rochas superficial, solo colapsível e terrenos muito inclinados.

\section{REFERÊNCIAS BIBLIOGRÁFICAS}

BRUNETTI, Michele et al. Temperature, precipitation and extreme events during the last century in Italy. Global and Planetary Change, vol. 40, 2004, p. 141-149.

CALTHORPE, Peter. Urbanism in the age of climate change. Washington D. C.: Island Press, 2010.

CHANGNON, S. A.; WESTCOTT, N. E. Heavy rainstorms in Chicago: increasing frequency, altered impacts, and future implications. Journal of American Water Resources Association, vol. 38, issue 5, October, 2002 , p. 1467-1475.

CITY OF PORTLAND. Stormwater Management Manual. Revision 4, August 1, 2008. Disponível em: <http://www.portlandonline.com/bes/index.cfm?c=47952>. Acesso em: abr. 2011.

COHEN, Joel E. Human population: the next half century. Science Magazine, vol. 302, p. 1172-1175.

CORMIER, Nathaniel S.; PELLEGRINO, Paulo Renato Mesquita. Infraestrutura verde: uma estratégia paisagística para água urbana. Paisagem e Ambiente: ensaios, n. 25, 2008, São Paulo: FAUUSP, p. 127-142.

CUBASCH, J.T. et al. Projections of future climate change. In: Climate change 2001 : the scientific basis. Cambridge University Press, Cambridge, U.K., p. 525-582.

DEBUSK, K. M.; WYNN, T. M. Stormwater Bioretention for Runoff Quality and Quantity Mitigation. Journal of Environmental Engineering, March, 2011, p. 1-27.

DEL GENIO, Anthony D.; LACIS, Andrew A.; RUEDY, Reto A. Simulations of the effect of a warmer climate on atmospheric humidity. Nature, vol. 351, May, 1991, p. 382-385.

DENAULT, Catherine; MILLAR, Robert G.; LENCE, Barbara J. Assessment of Possible Impacts of Climate Change in an Urban Catchment. Journal of American Water Resources Association, June, 2006, p. 685-697.

DIETZ, Michael E. Low impact development practices: a review of current research and recommendations for future directions. In: Water Air Soil Pollut, vol. 186, 2007, p. 351-363.

DOUGLAS, lan et al. Unjust waters: climate change, flooding and the urban poor in Africa. In: Environment and Urbanization, 2008, p. 120-187. 
DRAMSTAD, Wenche E.; OLSON, James D.; FORMAN, Richard, T.T. Landscape ecology principles in landscape architecture and land-use planning. Island Press, Washington, DC.: Harvard University Graduate School of Design, 1996. 80 p.

DUFEK, A. S.; AMBRIZZI, T. Precipitation variability in São Paulo State, Brazil. Theoretical and Applied Climatology, vol. 93, 2008, p. 167-178.

EMORI, S; BROWN, S. J. Dynamic and thermodynamic changes in mean and extreme precipitation under changed climate. Geophysical Research Letters, vol. 32, L17706, p. 1-5.

FARAM, M. G. et al. Appropriate drainage systems for a changing climate. Engineering Sustainability, vol. 163, June 2010, issue ES2, p. 107-116.

FREI, Christoph et al. Heavy precipitation processes in a warmer climate. Geophysical Research Letters, vol. 25, n. 9, May, 1998, p. 1431-1434.

GRIMM, Alice M. Interannual climate variability in South America: impacts on seasonal precipitation, extreme events, and possible effects of climate change. Stochastic Environmental Research and Risk Assessment, vol. 25, 2011 , p. 537-554.

GUO, Yping M. Updating rainfall IDF relationships to maintain urban drainage design standards. Journal of Hydrologic Engineering, September/October, 2006, p. 506-509.

HA, Simon J.; STENSTROM, Michael K. Predictive modeling of storm-water runoff quantity and quality for a large urban watershed. Journal of Environmental Engineering, September, 2008, p. 703-701.

INTERGOVERNMENTAL PANEL ON CLIMATE CHANGE (IPCC). Summary for Policymakers. Genebra: IPCC/ UNEP/WMO, 2007.

MAILHOT, Alain; DUCHESNE, Sophie. Design criteria of urban drainage infrastructures under climate change. Journal of Water Resources, Planning and Management. March/April, 2010, p. 201-208.

MARENGO, J. A. et al. Future change of temperature and precipitation extremes in South America as derived from the PRECIS regional climate modeling system. International Journal of Climatology, vol. 29, 2009. p. 2241 2255 .

MEEHL, Gerald. A. et al. Global climate projections. In: Climate change 2007: the physical science basis. Cambridge University Press, Cambridge, U.K, p. 749-845.

NASCIMENTO, N. O.; BAPTISTA, M. B. Técnicas compensatórias em águas pluviais. In: RIGHETTO, Antonio Marozzi (Coord.). Manejo de águas pluviais. Rio de Janeiro: ABES, Projeto PROSAB, 2009. 398 p.

NIEMCZYNOWICZ, Janusz. Impact of the greenhouse effect on sewerage systems - Lund case study. Journal of Hydrological Sciences, vol. 34, p. 651-666.

NOBRE, et al. Vulnerabilidade das megacidades brasileiras às mudanças climáticas: Região Metropolitana de São Paulo - Sumário Executivo. INPE / UNICAMP / USP / IPT / UNESP. Julho, 2010. Disponível em: <http:// www.inpe.br/noticias/arquivos/pdf/megacidades.pdf>. Acesso em: mai. 2011.

NOVOTNY, Vladimir; AHERN, Jack; BROWN, Paul. Water centric sustainable communities: planning, retrofitting, and building the next urban environment. New Jersey: John Wiley Inc. 2010. 624 p.

PINTO, Liliane L. A. O desempenho de pavimentos porosos como medida mitigadora da impermeabilização do solo urbano. 2011 . 255 f. Tese (Doutorado em Engenharia Hidráulica) - Escola Politécnica da Universidade de São Paulo, São Paulo, 2011.

PHD. Qualidade da Água em Reservatórios de Cheias Urbanas. São Paulo: Departamento de Engenharia Hidráulica e Sanitária-Escola Politécnica-USP, 2008.

RE, Mariano; BARROS, Vicente Ricardo. Extreme rainfalls in SE South America. Climatic Change, vol. 96, 2009, p. 119-136.

RILEY, Ann L. Restoring streams in cities: a guide for planners, policymakers, and citizens. Washington D.C.: Island Press, 1998

ROESNER, Larry A., BLEDSOE, Brian P.; BRASHEAR, Robert W. Are Best Management Practices really environmentally friendly? Journal of Water Resources Planning and Management, May/June 2001, p. 150-154.

SERVIÇO AUTÔNOMO MUNICIPAL DE ÁGUA E SANEAMENTO AMBIENTAL (SAMASA). Delimitação da Bacia de Contribuição do Reservatório Bom Pastor. Santo André: Departamento de Planejamento e Obras, 2006.

SCHOLZ, Miklas; YANG, Qinli. Guidance on variables characterising water bodies including sustainable flood retention basins. Landscape and Urban Planning, 98, 2010, p. 190-199. 
VIRGILIS, Afonso L. C. Procedimentos de projeto e execução de pavimentos permeáveis visando retenção e amortecimento de picos de cheias. 2009. 191 p. Dissertação (Mestrado em Engenharia de Transportes) - Escola Politécnica da Universidade de São Paulo, São Paulo, 2009.

WATERS, Darren et al. Adaptation of a Storm Drainage System to Accommodate Increased Rainfall Resulting from Climate Change. Journal of Environmental Planning and Management, vol. 46: 5, p. 755-770.

WEISS, Peter T. Weiss; GULLIVER, John S.; ERICKSON, Andrew J. Cost and pollutant removal of storm-water treatment practices. Journal of Water Resources Planning and Management, May/June 2007, p. 218-229.

WILBY, R. L. A review of climate change impacts on the built environment. Built Environment, vol. 33. n. 1, 2007, p. $31-45$. 
Newton Celio Becker Moura, Paulo Renato Mesquita Pellegrino

e José Rodolfo Scarati Martins 